\title{
Research on the market development path of intelligent medical industry under the background of aging
}

\author{
Linfeng WU ${ }^{1, a^{*}}$, Zihan $\mathrm{YU}^{2, \mathrm{~b}}$ and Peng ZHANG ${ }^{1, \mathrm{a}, \text { Chenxia KAN }}{ }^{1, \mathrm{a}}$ \\ 1,3,4 School of Electrical and Mechanical Engineering, Hohai University, ChangZhou, JiangSu, \\ China; ${ }^{2}$ School of Internet of things Engineering, Hohai University, ChangZhou, JiangSu, China \\ a1980893296@qq.com, b2531967292@qq.com, \\ c1135401844@qq.com, ${ }^{\mathrm{k} k k k k c c c c x x x x k x @ 163 . c o m}$ \\ * Linfeng WU
}

Keywords: intelligent medical, aging, market background, development path.

\begin{abstract}
This document explains and demonstrates from the elderly, intelligent medical service market capacity and the development status of intelligent medical service system in three aspects of the elderly intelligent medical industry market development background analysis, put forward on the basis of intelligent medical industry development path of the elderly. The study found that the elderly medical service market capacity is large, intelligent medical service system needs to be improved. Recommends that the government strengthen the construction of the elderly medical service system, improve top-level design, promote the medical service system and pension services industry collaborative development; enterprises take advantage of policy, try to launch pilot services, supporting the development of services, the integration of data sources, the formation of health data system, improve the status quo of intelligent medical service.
\end{abstract}

\section{Introduction}

With the popularity of artificial intelligence and the breakthrough of mobile Internet in recent years, the birth of intelligent medical, medical service process more intelligent, and spawned a series of specialized intelligent medical products for the elderly, such as smart box, smart bracelet. With the aging of the population, to solve the medical problems of artificial intelligence especially convenient. The domestic and foreign research on the elderly medical focus on health care, but relatively little research on the intelligent medical products. Do the elderly medical service, is an important content to cope with an aging population. This paper aims at the big data market environment, analyzing the current situation of the development of intelligent medical market of elderly people, and puts forward the feasible strategic measures from two angles of government and enterprises.

\section{Background of intelligent medical market development status of the elderly}

\subsection{The aging of China's population is serious and chronic diseases are frequent in the elderly}

According to the data from the sixth national census, there are approximately 1.37 billion people in China, of which the form of aging is severe. The number of elderly people in China ranks first in the world, and the ageing rate is the fastest in the world. The specificity of dealing with aging is also unique. The aging of the population is a major problem faced by all countries in the world. The Research Report on the Prediction of the Development Trend of Population Aging in China issued by the National Committee on Ageing in 2006 pointed out that the 21st century is an era of aging population. China entered the aging society in 1999 and is one of the developing countries that entered the aging society earlier. China is also the country with the oldest population in the world. The low fertility rate, the aging of the population structure and the lagging of the medical security system have become a major hidden danger in the future development. 
According to the National Population Development Strategy Research Report, the population of elderly people over the age of 60 has reached 143 million, accounting for $11 \%$ of the total population. By 2020, the number of elderly people over the age of 60 will reach 234 million, with the proportion rising from $9.9 \%$ in 2000 to $16.0 \%$; the population aged 65 and above will reach 164 million, which will increase from $6.7 \%$ in 2000 to $11.2 \%$. It is estimated that a peak platform for the elderly population will form in the late 1940s, with 430 million people over the age of 60 reaching $30 \%$, and more than 320 million people over the age of 65 , accounting for $22 \%$, with an average of 3 to 4 people each. There is an elderly person. In 2020 and 2050, the elderly aged over 80 will reach 22 million and 83 million people, respectively.

The continued seriousness of the aging population will surely bring about some new conflicts and pressures. It will pose new challenges to the development of the economy, society and science and technology, develop smart medical service products, promote the comprehensive construction of the medical service system, and meet the huge needs of the elderly population.

\subsection{The market capacity of elderly medical services continues to grow}

In recent years, as the living standards of the residents have increased, the number of elderly people suffering from diseases has also increased, and the capacity of the medical market will continue to expand. According to the survey, the consumption data of the elderly care market in China is as follows: In 2014, the annual consumption demand was 1 trillion yuan, and the annual supply was only 100 billion yuan; according to the data, the market size is still rapidly expanding at a rate of 10 times, 2020. The annual demand for annual consumption in the elderly market is 2 trillion yuan, and by 2030 it will reach 8 trillion yuan. This market size cannot be overlooked, indicating that the supply of elderly medical care and retirement services market is far from sufficient, and the participation of social capital is not high. It also shows that China's medical service industry for the elderly contains huge business opportunities.

\subsection{Intelligent medical service system needs to be improved}

At present, the development of intelligent medical system in China is divided into seven levels: one is the business management system, including hospital fees and drug management system; two is the electronic medical record system, including patient information, image information; three is the clinical application system, including the entry of computer system (CPOE) and other medical doctors; four is a chronic disease management system; the five is the regional health information exchange system; six is a clinical decision support system; seven is the public health system. Overall, Chinese in the first, second stage to the third stage development stage, there is no real sense of CPOE, is the lack of effective data, data standards are not unified, and suppliers lack clinical background, from standard to practical application also lack of standard guidelines. Chinese to from the second stage into the fifth stage, involving many industry standards and data exchange standards, this is the future of the aspects need to be improved.

\section{Elderly intelligent medical market development path}

\subsection{Government level}

(1) Strengthen the establishment of an elderly medical service system and improve top-level design

The current and future period of time, promote the construction of the elderly intelligent medical service system, the key is to promote the construction of system thinking, the elderly medical service to the medical and health system is the key to promote the health and pension services, combined with a large team of doctors to sink to promote medical care service system construction, basic to adhere to the public welfare oriented as the premise to play double the role of government and market, to the satisfaction of the public is fundamental to strengthen policy evaluation. Need to break through for 
the past misunderstanding of elderly medical service system, medical service system, set up the concept of the elderly, a full range of continuous.

(2) Promote the medical service system and pension services industry collaborative development

Intelligent medical and pension services combined, is a major livelihood issue of common concern, is a positive response to population aging, is China's economic development under the new normal is an important economic growth point. At present, pension and medical service of medical health and pension service in China is relatively independent of each other, can not meet the needs of the elderly. To solve this problem, need to promote the coordinated development of medical services and pension services.

\subsection{Corporate level}

(1) Using the policy advantages and trying to deliver service pilots

The enterprise can be in more advanced hospitals in the pilot launch. For example, can realize the medical record information, patient information, patient information such as real-time recording, transmission and processing of the network utilization, between the hospital and the hospital internal, timely and effectively sharing relevant information, this is for the implementation of telemedicine, expert consultation and referral hospital can play a good supporting role this is mainly due to the policy level, to promote and support technology.

\section{(2) Integrating data sources and constructing a health data system}

The data integration of medical inspection, so that everyone has their own electronic health records, should be standardized, solve the problems of big data cloud platform. Advance of artificial intelligence and intelligent health management and medical supervision related to the ubiquitous network, networking, sensor networks and mobile Internet combined. How to use the data for diagnosis, evaluation and treatment intervention. A lot of medical information, how to integrate the data into the key issues. According to the problem of aging, break through the key technology of artificial intelligence, enhance the ability of intelligent medical supplies. Efforts to strengthen the intelligent medical and health industry chain cultivation, guide the intelligent medical and health industry cluster development, play the role of advanced technology demonstration of artificial intelligence.

\section{Summary}

The elderly medical service is a perplexing system engineering, involving all aspects, based on the actual needs, overall planning. In the background of aging, the face of the vast medical service market of China's elderly capacity, intelligent medical development is not yet mature, elderly medical services still exist fragmentation, not a system problem in the process of advancing. At the government level, for the elderly medical service system has been the lack of systematic and overall planning and comprehensive top-level design, the related department alone, can not form the overall force, the lack of forward-looking and predictable, there is a big gap between ideas, innovation and the requirements of the times, there are still some outstanding problems of intelligent medical services. With big data, to solve these problems, enterprises should also provide more convenient and diverse health care services for people, choice of medical service, can help reduce medical costs. Intelligent medical will help us more reasonable allocation of medical resources.

\section{Acknowledgement}

This research was financially supported by the National College Students' Innovation Training Project: "IKEA Kang Medical Electronic Technology Co., Ltd.", 20161029411. 


\section{References}

[1] S. K. Goyal, An integrated inventory model for a single supplier-single customer problem, International Journal of Production Research, vol.15, pp. 107-111, 1977.

[2] A. Banerjee, A joint economic-lot-size model for purchaser and vendor, Decision Sciences, vol.17, pp. 292-311, 1986.

[3] S. K. Goyal, A joint economic-lot-size model for purchaser and vendor: A comment, Decision Sciences, vol.19, pp. 236-241, 1988.

[4] R. M. Hill, The single-vendor single-buyer integrated production-inventory model with a generalized policy, European Journal of Operational Research, vol. 97, pp. 493-499, 1997.

[5] S.L. Kim and D. Ha, A JIT lot-splitting model for supply chain management: Enhancing buyer-supplier linkage, Int. J. Production Economics, vol. 86, pp. 1-10, 2003.

[6] M. Ben-Daya, M. Darwis, and K. Ertogral, The joint economic lot sizing problem: Review and extensions, European Journal of Operational Research, vol. 185, pp. 726-742, 2008.

[7] L. Lu, A one-vendor multi-buyer integrated inventory model, European Journal of Operational Research, vol. 81, pp. 312-323, 1995.

[8] H. Siajadi, R. N. Ibrahim, and P. B. Lochert, A single-vendor multiple-buyer inventory model with a multiple-shipment policy, Int J Adv Manuf Technol, vol. 27, pp. 1030-1037, 2006.

[9] M. Hoque, Synchronization in the single-manufacturer multi-buyer integrated inventory supply chain, European Journal of Operational Research, vol. 188, pp. 811-825, 2008.

[10]T. Kim, Y. Hong, and S. Y. Chang, Joint economic procurement--production-delivery policy for multiple items in a single-manufacturer, multiple-retailer system, Int. J. Production Economics, vol.103, pp. 199-208, 2006.

[11]M. Y. Jaber and S. K. Goyal, Coordinating a three-level supply chain with multiple suppliers, a vendor and multiple buyers, Int. J. Production Economics, vol. 116, pp. 95-103, 2008. 